\title{
DETERMINING EFFECTSD OF AIR-POWER DUSTER ON DISTRIBUTION PATTERN OF EGYPTIAN CLOVER SEEDS
}

Sahhar,E. A. S.

Agric. Engineering Dept. Fac. of Agric., Ain Shams Univ., Shoubra ElKheima, Cairo, Egypt.

\begin{abstract}
Predictability of Egyptian clover seeds distribution patterns is of interest from the precision seeding as well as the economical point of view. To ensure a constant level of uniformity of distribution patterns in the field. Moreover, due to the lake of related information to the physical and aerodynamic properties of Egyptian clover seeds and its importance for the development of seeding machines that are related to these seeds broadcasting, the present work have the objective to study the effects of the operation factors of air-power duster on distribution patterns of the clover seeds. It was observed that: In general, the knapsack type power duster proved function satisfactorily in Egyptian clover seeds broadcasting under the test conditions. The most important factor affecting seeding rate and index of irregularity is the travel speed of operator. A low speed of $1.03 \mathrm{~km} / \mathrm{h}$ gave a higher seeding rate $\left(2.1 \mathrm{~g} / \mathrm{m}^{2}\right)$ and lower index of irregularity (44\%), while the high speed of $2.46 \mathrm{~km} / \mathrm{h}$ gave lower seeding rate $\left(1.5 \mathrm{~g} / \mathrm{m}^{2}\right)$ and higher index of irregularity $(48 \%)$. The preferred operation factors to broadcasting the Egyptian clover seeds by using knapsack type power duster were found to be air velocity of $30 \mathrm{~m} / \mathrm{s}$; discharge seed rate of $0.71 \mathrm{~kg} / \mathrm{min}$; peripheral velocity of blow-head arm of $0.42 \mathrm{~m} / \mathrm{s}$; orientation angle of blow-head arm of $30^{\circ}$; seeds moisture content of $11.77 \%$ and overlapping percent between distribution patterns of $40 \%$.
\end{abstract}

Keywords: Egyptian clover, distribution patterns, seeding rate, index of irregularity, overlapping percent, knapsack type power duster.

\section{INTRODUCTION}

Clover crop is considered the most important green forage crops in Egypt. It plays a vital role in animal feeding. The cultivated area of clover crop in 2005 amounted 2.24 million feddans, it produced about 55 million tons according to Agricultural Extension Issue, (2006).

Testing knapsack type power duster in broadcasting seeds of Egyptian clover and obtaining a pattern with an acceptable uniformity is a process affected by changes in seeding factors, such as travel speed of operator, broadcasting air velocity, discharge rate of seeds, peripheral velocity and orientation angle of blow-head, seeds moisture content and overlapping percent. Distribution patterns of the seeds broadcasting process would allow a greater understanding of the process and lead to study the effects of machine adjustment, and to ability to develop recommendations to farmers for initial setup and calibration of knapsack type power dusters or mist sprayers to be used with broadcasting seeds. Many researchers have studied the movement of particles in an air stream to quantity the physical properties which optimize spread width. Law and Collier (1973) developed a technique for using an elutriator to measure the terminal velocity of agricultural particulates. Bilanski et al. (1962), Griffis et al. (1983), and Law and Collier (1973) showed that the large, heavier particles would have a higher terminal velocity than smaller, lighter particles. Lee and Yates (1977) showed that 
particles with higher terminal velocities would travel farther than particles with a lower terminal velocity. They also showed that for a selected initial velocity, the optimum particle sizes for producing wide swaths were those having terminal velocities of 15 to $20 \mathrm{~m} / \mathrm{s}$. Yates et al. (1973) showed that terminal velocity of a material is one of the important variables affecting the maximum lateral spread.

The purpose of this study was to investigate the possibility of using air stream of knapsack type power duster to broadcast seeds of Egyptian clover for optimum crop yields with minimum labor requirements. The specific objectives are to: 1) determine the physical characteristics of the Egyptian clover seeds; 2) determine the aerodynamic parameters: terminal velocity and resistance and drag coefficients for clover seeds and 3 ) investigate the factors affecting broadcasting process for clover seeds.

\section{MATERIAL AND METHODS}

Broadcasting machine: A lightweight knapsack type power machine with 2 cycle air-cooled $2.25 \mathrm{~kW}$ engine is used as a seeds broadcaster (Fig. 1). A seeds tank is fixed on the air outlet of straight tube of blow-head. This tank has a rectangular orifice with adjustable feed gate in the bottom to discharge the seeds into the air stream. The air flowed from fan case makes enough strong wind to transport and broadcast the seeds on field surface. Air velocity in the blow-head tube was controlled by the throttle lever of the engine.

Seed material: Egyptian clover "Berseem" seeds (Trifolium Alexandrian, L.) namely "Mesquawy مسقاوي" were submitted from Gene Bank, Agricultural Research Center and used in this investigation.

Table 1: Physical characteristics of Egyptian clover seeds

\begin{tabular}{|c|c|c|c|}
\hline \multirow{2}{*}{ Physical characteristics } & \multicolumn{3}{|c|}{ Soakage time, hour } \\
\hline & Zero & 4 & 16 \\
\hline \multicolumn{4}{|l|}{ Axial dimensions, mm } \\
\hline Major dia. & $2.276 \pm 0.148$ & $2.844 \pm 0.263$ & $3.340 \pm 0277$ \\
\hline Intermediate dia. & $1.660 \pm 0.122$ & $3.003 \pm 0.168$ & $2.298 \pm 0.160$ \\
\hline Minor dia. & $1.251 \pm 0.115$ & $1.351 \pm 0.138$ & $1.556 \pm 0.184$ \\
\hline Geometry dia. & $1.676 \pm 0.094$ & $1.970 \pm 0.127$ & $2.278 \pm 0.159$ \\
\hline Volume, $\mathrm{mm}^{3}$ & $2.486 \pm 0.408$ & $4.050 \pm 0.772$ & $6.270 \pm 1.273$ \\
\hline Mass, $\mathbf{g}$ & $3.47 \times 10^{-4} \pm 1.95 \times 10^{-5}$ & $7.19 \times 10^{-4} \pm 4.64 \times 10^{-5}$ & $7.34 \times 10^{-4} \pm 5.13 \times 10^{-5}$ \\
\hline Moisture content, \% & \begin{tabular}{|c|}
11.72 \\
\end{tabular} & 52.66 & 63.90 \\
\hline Density, $\mathrm{g} / \mathrm{mm}^{3}$ & $8.69 \times 10-7 \pm 1.88 \times 10-7$ & $2.95 \times 10-6 \pm 7.43 \times 10-7$ & $4.67 \times 10-6 \pm 1.24 \times 10-6$ \\
\hline Sphericity, \% & $73.77 \pm 4.08$ & $69.57 \pm 4.92$ & $68.66 \pm 3.807$ \\
\hline Projected area, $\mathrm{mm}^{2}$ & $2.557 \pm 0.810$ & $6.845 \pm 2.546$ & $16.483 \pm 6.336$ \\
\hline
\end{tabular}

In the Table 1, the results of the physical characteristics of clover seeds, with moisture contents of $11.72,52.66$, and $63.90 \%$ wet basis (by taking $\mathrm{m}$. c. as a function of soakage times of zero, 4 and 16 hours), are presented. Clover seeds had a sphericity index of $73.77,69.57$ and $68.66 \%$ at seed moisture contents of $11.72,52.66$ and $63.90 \%$ resp. (Table 1 ). Clover seeds can be treated as an elliptical for analytical calculations because of their medium sphericity index. 
The elutriator and air velocity measurement: to study the aerodynamic properties of clover seeds an elutriator was designed and constructed (Fig. 2). The elutriator consists of a $50 \mathrm{~cm}$ long plexiglass vertical tube with a diameter of $4 \mathrm{~cm}$ in which an airflow is supplied by an air pump. The air velocity was controlled with the valve. A stainless steel screen with bore size of $0.55 \mathrm{~mm}$ (about 45 meshes) was used in the bottom of the vertical tube and supported the seeds until the test began. Input air was adjusted until the seeds began to float. The air velocities at which all the seeds became suspended and the flowed from blow-head tube of broadcasting machine were measured with a rotor of wind anemometer, where the accuracy of anemometer was $1.0 \mathrm{~m} / \mathrm{s}$. In the Table 2, the results of the aerodynamic properties of seeds, with moisture contents of $11.77,52.66$ and $63.90 \%$ wet basis, are presented.

Table 2: Aerodynamic properties of Egyptian clover seeds

\begin{tabular}{|c|c|c|c|}
\hline Moisture content of seeds, $\%$ & 11.72 & 52.66 & 63.90 \\
\hline Terminal air velocity (measured) “ $V_{t}$ ", $\mathrm{m} / \mathrm{s}$ & $0.88 \pm 0.079$ & $0.96 \pm 0.052$ & $1.03 \pm 0.142$ \\
\hline \begin{tabular}{|l|} 
Aerodynamic resistance \\
coefficient (calculated) “k”, g/m.
\end{tabular} & $\begin{array}{l}4.48 \times 10^{-6} \\
\pm 7.76 \times 10^{-7}\end{array}$ & $\begin{array}{l}6.65 \times 10^{-6} \\
\pm 7.27 \times 10^{-7}\end{array}$ & $\begin{array}{l}7.11 \times 10^{-6} \\
\pm 1.76 \times 10^{-7}\end{array}$ \\
\hline $\begin{array}{l}\text { Aerodynamic drag } \\
\text { coefficient (calculated) “ } C_{d} \text { ”, g/m. }\end{array}$ & $\begin{array}{l}2.71 \times 10^{-6} \\
\pm 4.69 \times 10^{-7}\end{array}$ & $\begin{array}{r}1.48 \times 10^{-6} \\
\pm 1.64 \times 10^{-7}\end{array}$ & $\begin{array}{c}6.67 \times 10^{-6} \\
\pm 1.65 \times 10^{-7}\end{array}$ \\
\hline
\end{tabular}

Seed weight and its moisture content: An electrical balance was used for the determination of the seed weight and its moisture contents. Its capacity sensitive was $300 \mathrm{~g}$ and accuracy of $0.01 \mathrm{~g}$. The moisture content of clover seeds was determined by using a sample of $25 \mathrm{~g}$ whole seeds after being placed in forced convection oven set at $70^{\circ} \mathrm{C}$ for 48 hours.

TEST PROCEDURE: The tests for investigating the operational quality of the air-power duster in clover seeds broadcasting were carried out in an Experimental Farm of dry soil belonging to the Fac. of Agric., Ain Shams Univ. Seeds were discharged from seeds tank into the air flowed from blowhead tube and the broadcasted seeds were collected in 70 catch cups with diameter of $12 \mathrm{~cm}$. The catch cups were distributed in row spacing of $1 \mathrm{~m}$ and $2 \mathrm{~m}$ between rows (Fig. 3 )

Three travel speeds of operator ranged form 1.03 to $2.46 \mathrm{~km} / \mathrm{h}$, three discharge seed rates of $0.6,1.8$ and $2.5 \mathrm{~kg} / \mathrm{min}$, three air velocities of blowhead of 16,30 and $45 \mathrm{~m} / \mathrm{s}$, four peripheral velocities of blow tube of 0.25 , $0.33,0.42$ and $0.63 \mathrm{~m} / \mathrm{s}$, and three orientation angles of blow tube of zero, 15 , and $30^{\circ}$ were used to evaluate the operational quality of the dusting machine for clover seeds broadcasting. Further experiments included studies on the effect of the soakage time of seeds with water $(0,4$ and 16 hours) to determine which seeds moisture content (11.72, 52.66 and $63.99 \%)$ was most acceptable to the broadcasting process. After the seeds have been broadcasted on the field surface, seeds are gathered from each of the cups and then weighed. The average value of seeding rate and index of irregularity (broadcasting uniformity) were calculated. In addition, the seeds broadcasting using air-power duster was compared with manual broadcasting. Moreover, the investigation included studies on the effect of the overlapping percentage 
Sahhar,E. A. S.

between two distribution patterns under the preferred conditions of broadcasting process to determine which overlapping appropriate to the broadcasting machine.

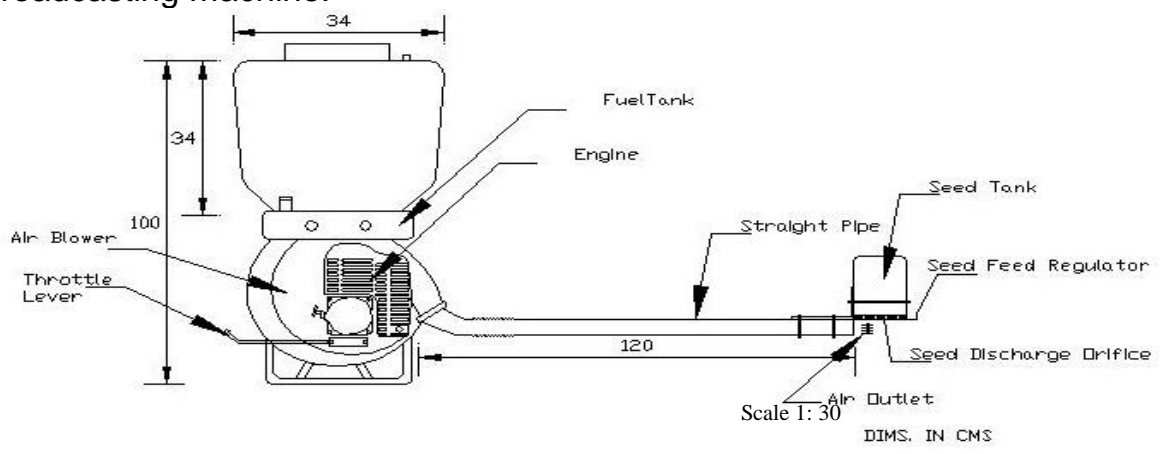

Fig 1: Knapsack type power broadcaster.

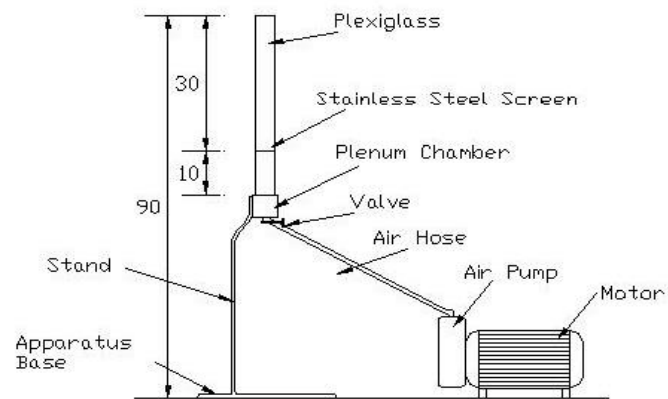

DIMS. IN CMS

Fig 2: An apparatus for measuring the terminal ${ }^{\mathrm{S} a l}{ }^{20} \mathrm{vel}$ (ocity of clover seeds.

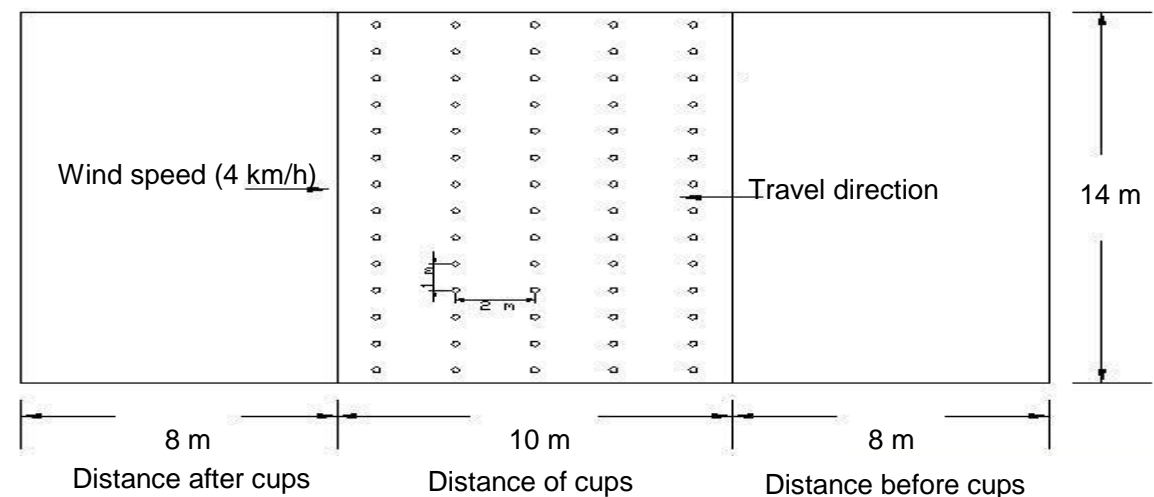

Fig 3: Layout area test of distribution pattern of clover seeds.

The main calculations, which were carried out, can be summarized as follows:

1- PHYSICAL CHARACTERISTICS OF CLOVER SEEDS:

Dimensions: the dimensions of the seeds were measured in three directions using a digital caliper gauge $(0.01 \mathrm{~mm})$. The major diameter " $a$ " 
was the length of the seed, the intermediate diameter " $b$ " was the width, and the minor diameter " $c$ " was the thickness of the seed. The minor diameter was taken perpendicular to the intermediate diameter. The caliper was held perpendicular to the direction of the dimension being measured. Dimensions were measured on 50 seeds. The following relations were used to calculate some physical characteristics as follows (Mohsenin, 1986).

$$
\begin{aligned}
& \text { Geometry diameter of seed }=(\boldsymbol{a} \cdot \boldsymbol{b} \cdot \boldsymbol{c})^{1 / 3} \\
& \text { Seed volume }=\frac{\pi}{\boldsymbol{\sigma}} \boldsymbol{a \cdot b \cdot c} \\
& \text { Seed sphericity }=\frac{(\boldsymbol{a} \cdot \boldsymbol{b} \cdot \boldsymbol{c})^{1 / 3}}{\boldsymbol{a}} \times \boldsymbol{Y O O} \\
& \text { Projected area of seed }=1.21\left(\frac{\pi}{6} \text { a.b.c }\right)^{2 / 3}
\end{aligned}
$$

Seed mass and true density: Then the mass of so seeds was recorded and the true density of the seeds was computed by dividing the mass by computed volume of seed.

2- Aerodynamic characteristics of clover seeds: The terminal or critical velocity " $V$ " of clover seeds was measured on ten samples, then the aerodynamic resistance and drag coefficients of clover seed were calculated from the measured terminal velocity using the following equations (Law and Collier, 1973; Mohsenin, 1986 and Omobuwajo et al., 1999):

Aerodynamic resistance coefficient " $\boldsymbol{k}$ "

Aerodynamic drag coefficient " $\boldsymbol{C}_{d}$ " $=\frac{\mathbf{2 k}}{\boldsymbol{A} \text { pair }}$

Where, " $\boldsymbol{m}$ " is the seed mass in $\mathrm{g}$; " $\boldsymbol{g}$ " is the gravitational acceleration in $\mathrm{cm} / \mathrm{s}^{2}$; " $V$ " is the measured terminal velocity of seed in $\mathrm{cm} / \mathrm{s}$; " $\boldsymbol{A}$ " is the projected area of seed in $\mathrm{mm}^{2}$ and " $\boldsymbol{\rho}_{\text {air }}$ " is the air density in $\mathrm{g} / \mathrm{mm}^{3}$.

3- The index of irregularity of seeds distributed: The index of irregularity of distributed seeds " $\delta$ " is calculated by the following formula (Bernacki et al., 1972):

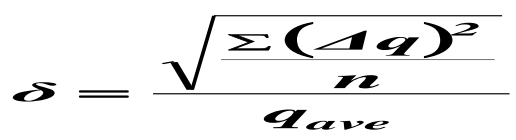

Where, " $n$ " is the number of catch cups; " $\Delta q$ " is the seed quantity deviations of particular cups from the average ones, and " $\boldsymbol{q}_{\boldsymbol{a v} \boldsymbol{e}}$ " is average value of the collected seeds in cups. 
Sahhar,E. A. S.

4- Average of seeding rate: The quantity of seeds covering 1.0 square meter of the field surface "qave" calculated as follows:

$$
\boldsymbol{q a v e}=\frac{\sum q}{\boldsymbol{n} \boldsymbol{A}_{\text {cup }}}
$$

Where, "Acup" is the cross section area of catch cup in $\mathrm{m}^{2}$.

5- Overlapping percentage: The overlap between the two distributions (Fig. 4 ) is expressed in terms of the overlapping percentage "OP' defined as (Amin et al., 1983):

$O P=(W / S-1) 100$

Where, " $\boldsymbol{W}$ ' is the broadcasting width of individual distribution pattern and ' $\boldsymbol{S}$ ' is the spacing between the travel direction axes.

6- Statistical analysis: The data were exposed to proper statistical analysis of the standard division of complete random design (Snedecor 1956).

\section{RESULTS AND DISCUSSION}

1- Travel speed of operator: The effect of travel speed of operator on the distribution pattern, seeding rate and index of irregularity for Egyptian clover seeds is shown in Figs. 5, 6 and 7. Figures indicate that increasing the travel speed from 1.03 to $2.46 \mathrm{~km} / \mathrm{h}$ tends to decrease both the seeding rate from 2.1 to $1.5 \mathrm{~g} / \mathrm{m} 2 \mathrm{resp}$. and increased the index of irregularity from 44 to $48 \%$ resp. for the broadcasting machine. The decrease in seeding rate values at higher travel speeds is due to increased the coverage area with still the discharge seed rate. While, the increase in index of irregularity values at higher travel speeds is attributed to decrease the seed quantity deviations from the average ones, which resulted in decreased the seeding rate. In addition, the results showed that the seeding rate and index of irregularity for manual broadcasting were more than that broadcasting machine by 15 and $33.3 \%$ resp. at travel speed of $1.10 \mathrm{~km} / \mathrm{h}$ (appropriate travel speed of operator during broadcasting process manually). This is due to the manual broadcasting gave the highest rates of discharge seeds and increased the overall average of seeding rate. The preferred travel speed of operator during broadcasting process for clover seeds by using knapsack duster was found to be $1.10 \mathrm{~km} / \mathrm{h}$ as it resulted in higher seeding rate and appropriate speed for walking operator in wet soil.

2- Air velocity of blow-head: Figures (8), (9) and (10) illustrates the results obtained of distribution pattern, seeding rate and index of irregularity with air velocities of blow-head. It can be noticed that the air velocity of $30 \mathrm{~m} / \mathrm{s}$ gave the highest values of seeding rate of $1.6 \mathrm{~g} / \mathrm{m}^{2}$ and consequently, a better distribution pattern compared with the other velocities. Meanwhile, the smallest values of seeding rate of 0.7 and $0.6 \mathrm{~g} / \mathrm{m}^{2}$ obtained at air velocities of 16 and $45 \mathrm{~m} / \mathrm{s}$; may be due to decreased the discharge seeds which resulted in increased the turbulence air action under the discharge orifice directly at smaller air velocities and increased the obstruction air stream for flowed seeds from seed tank at higher of air velocities. 


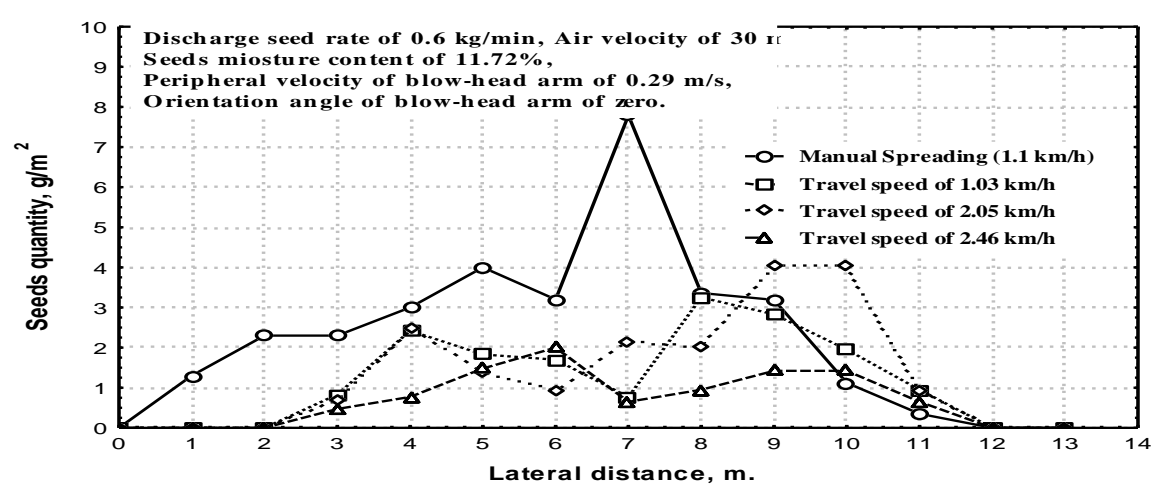

Fig. 5: Effect of travel speed of operator on the distribution pattern for Egyptian clover seeds.

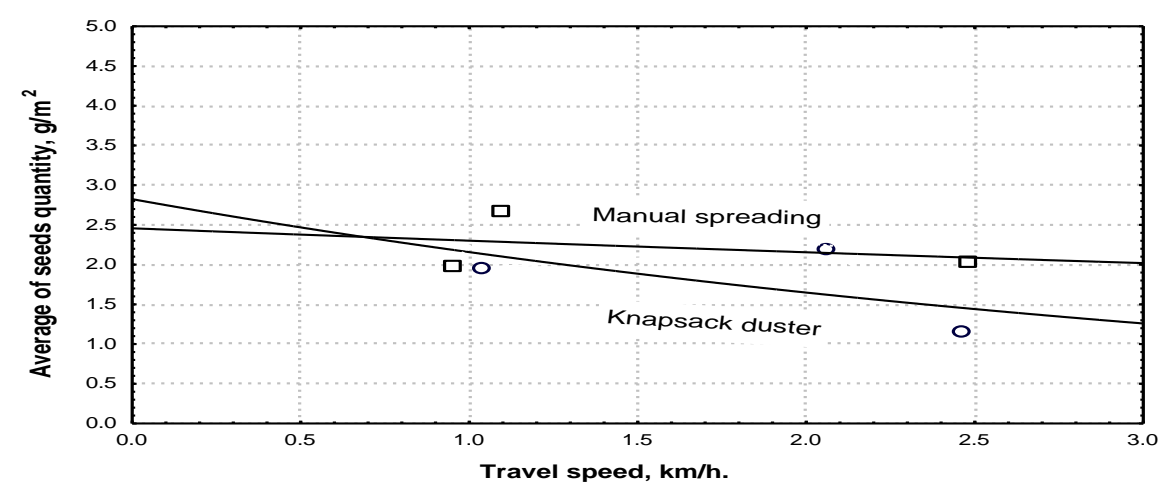

Fig. 6: Effect of travel speed of operator on the average of seeds quantity for clover seeds.

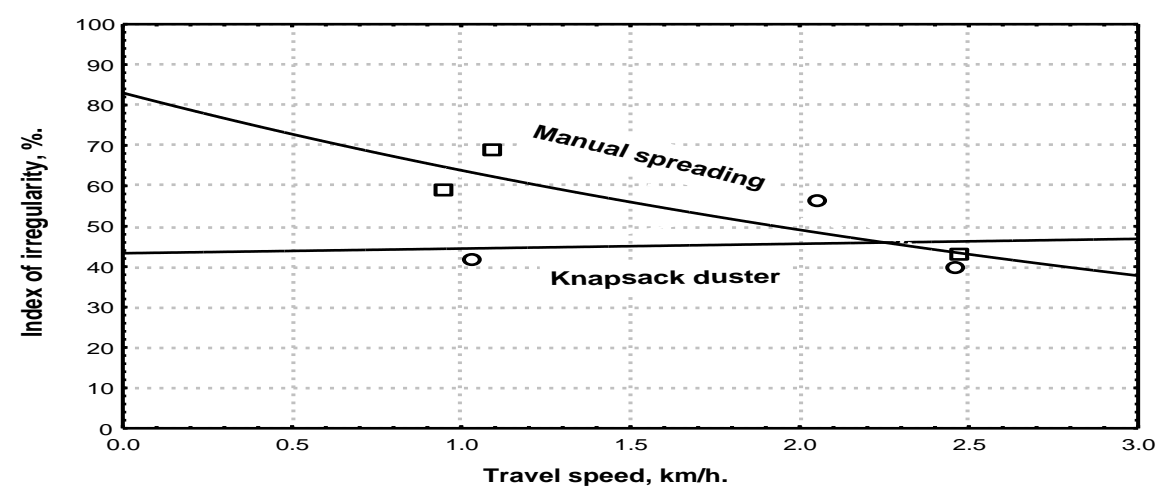

Fig. 7: Effect of travel speed of operator on the index of irregularity for clover seeds. 
Sahhar,E. A. S.

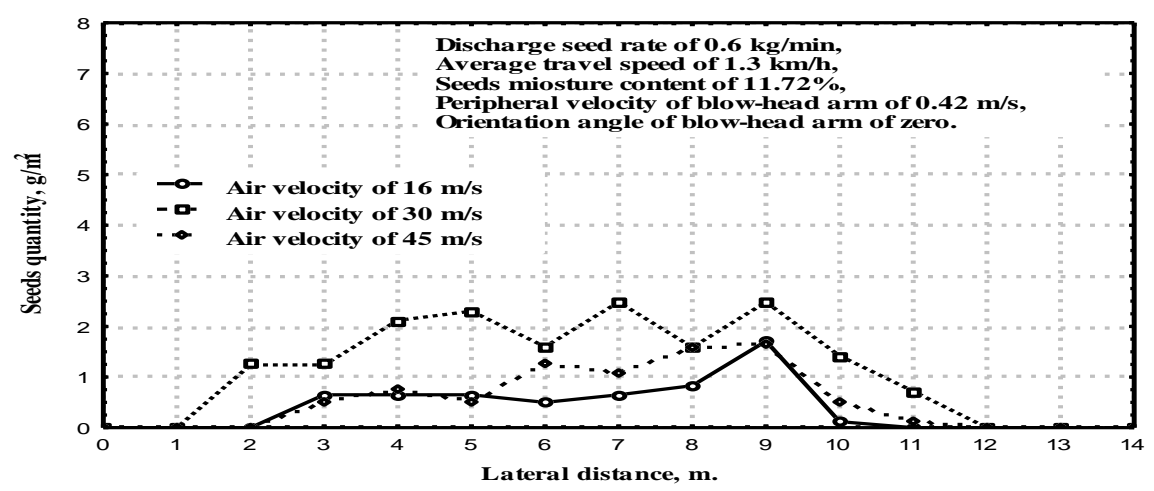

Fig. 8: Effect of air velocity on the distribution pattern for Egyptian clover seeds.

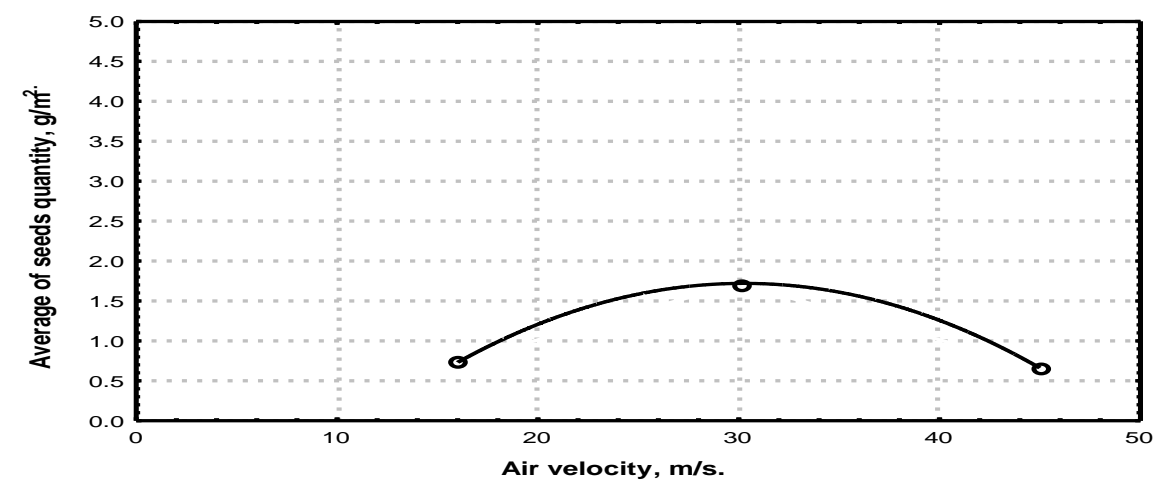

Fig. 9: Effect of air velocity on the average of seeds quantity for clover seeds.

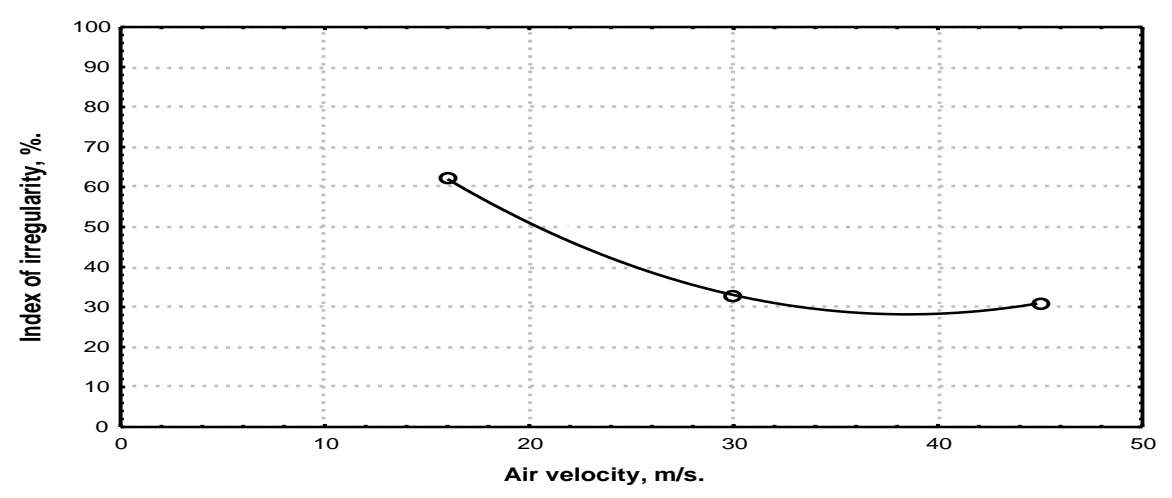

Fig. 10: Effect of air velocity on the index of irregularity for clover seeds.

The results also showed that the values of irregularity index for distributed seeds decreased from 61 to $30 \%$ by increasing the air velocities from 16 to 
$45 \mathrm{~m} / \mathrm{s}$ resp. due to decreased the overall average of seeding rate, as discussed before. Therefore, the optimum air velocity to broadcasting the Egyptian clover seeds is $30 \mathrm{~m} / \mathrm{s}$.

3- Discharge seed rate: The distribution pattern, seeding rate and index of irregularity for Egyptian clover seeds changes directly with the discharge seed rate as shown in Figs. (11), (12) and (13). The results showed that increasing the discharge seed rate from 0.6 to $2.5 \mathrm{~kg} / \mathrm{min}$. tends to increase the seeding rate from 0.6 to $2.9 \mathrm{~g} / \mathrm{m}^{2}$ resp. and increase the index of irregularity from 41 to $44 \%$ resp. The increase in seeding rate at higher discharge seed rates is attributed to increase the broadcasted seeds quantity on the unit area of field surface and consequently, the higher rates of discharge seed gave the better distribution pattern compared with the smaller rates. On the other hand, the increase in index of irregularity at higher discharge seed rates is attributed to increase the seeds intensity and increased the seed quantity deviations from the average ones. The adequate theoretical discharge seed rate of broadcasting process by using knapsack duster for clover seeds is estimated by taking the following assumptions: travel speed of operator $=1.10 \mathrm{~km} / \mathrm{h}$, broadcasting width $=10 \mathrm{~m}$, inasmuch as the one feddan needs to $13 \mathrm{~kg}$ clover seeds (according to Abdel-Gawad and Abo Shetaia, 1998), germination percent $=85 \%$ and purity percent $=$ $90 \%$ according (recommendations of Agriculture Ministry and Land Reclamation). Consequently, the theoretical performance rate of broadcasting machine is $183.33 \mathrm{~m}^{2} / \mathrm{min}$. and the seed intensity is $3.87 \mathrm{~g} / \mathrm{m}^{2}$. Therefore, the discharge seed rate is $709.5 \mathrm{~g} / \mathrm{min}(0.71 \mathrm{~kg} / \mathrm{min})$.

4- Peripheral velocity of blow-head arm: The values in Figs. (14), (15) and (16) were obtained at peripheral velocities of blow-head arm from 0.29 to $0.63 \mathrm{~m} / \mathrm{s}$. Throughout this range, greater peripheral velocity decreased the average of seeds quantity per square meter from 2 to $0.9 \mathrm{~g} / \mathrm{m}^{2}$ resp. and increased the index of irregularity from 40 to $54 \%$ resp. for broadcasting of clover seeds. The decrease in seeding rate at higher peripheral velocities of blow-head is referred to reduction the coverage time which required for unit area during broadcasting process. On the other hand, the increase in index of irregularity at higher peripheral velocities of blow-head is attributed to increase the seed quantity deviations from the average ones, which resulted in decreased the seeding rate. Fig. (14) shows the optimum peripheral velocity of blow-head arm during broadcasting process is $0.42 \mathrm{~m} / \mathrm{s}$ as it resulted in higher seeding rate $\left(1.55 \mathrm{~g} / \mathrm{m}^{2}\right)$ and lower index of irregularity $(30 \%)$ than any of the other peripheral velocities.

5- Orientation angle of blow-head arm: The effect of the orientation angle of blow-head arm on the distribution pattern, seeding rate and index of irregularity for broadcasting clover seeds is shown in Figs. (17), (18) and (19). The results showed little change in distribution patterns, no change in the seeding rate and slight increase in index of irregularity. Meanwhile, the average seeding rate was reached $1.65 \mathrm{~g} / \mathrm{m}^{2}$ at orientation angles of blowhead arm of zero degree (in horizontal position), $15^{\circ}$ and $30^{\circ}$. 


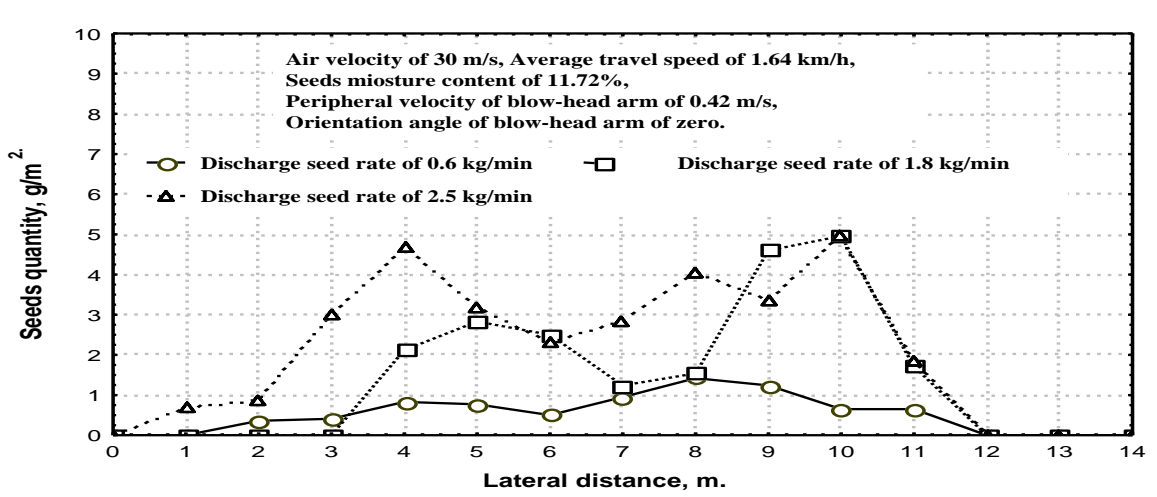

Fig. 11: Effect of discharge seed rate on the distribution pattern for Egyptian clover seeds.

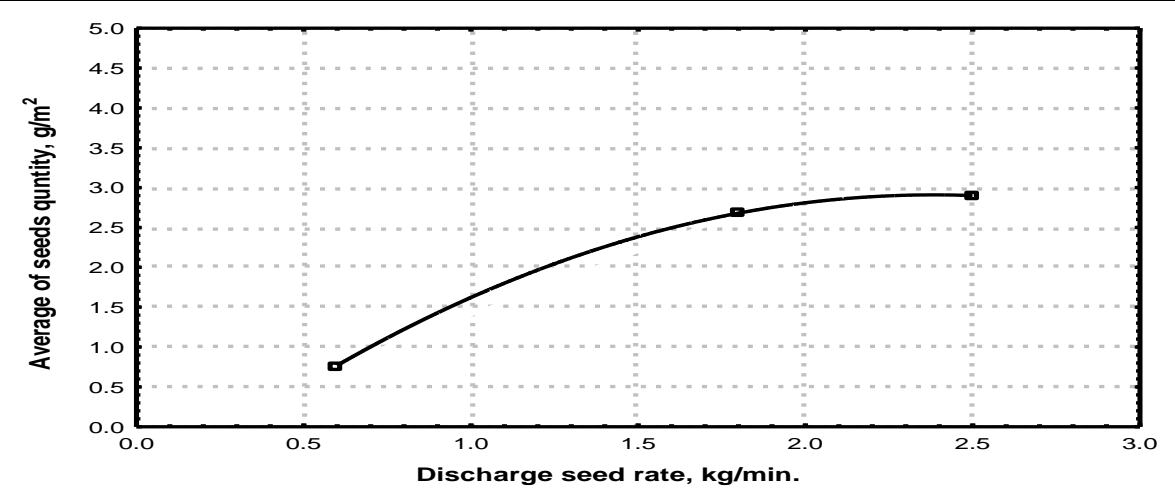

Fig. 12: Effect of discharge seed rate on the average of seeds quantity for clover seeds.

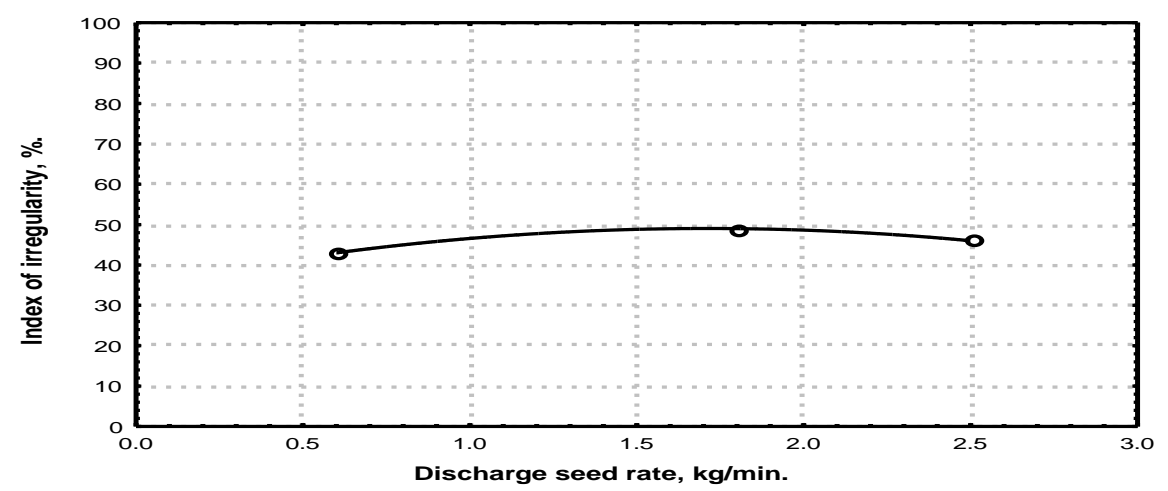

Fig. 13: Effect of discharge seed rate on the index of irregularity for clover seeds. 


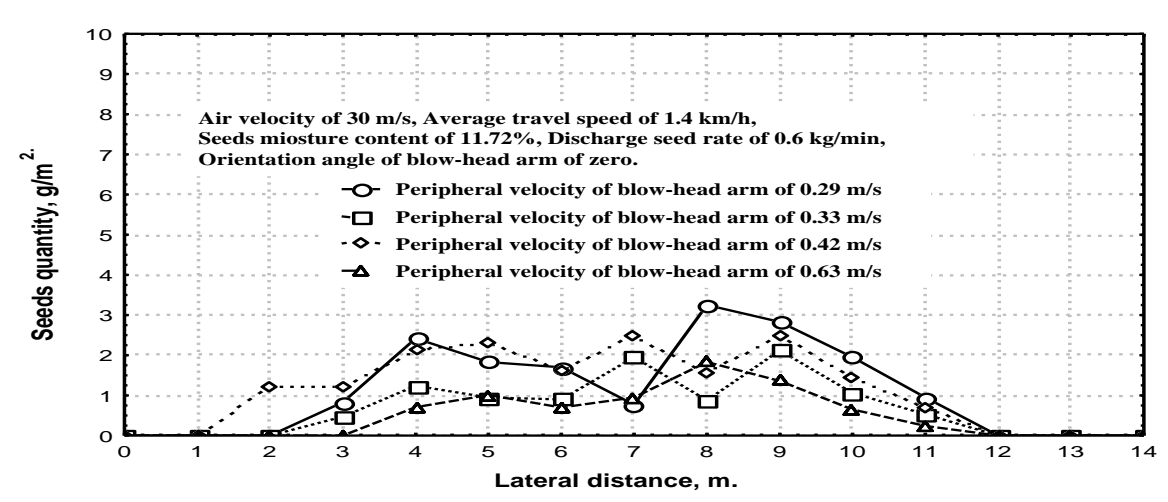

Fig. 14: Effect of peripheral velocity of blow-head arm on the distribution pattern for Egyptian clover seeds.

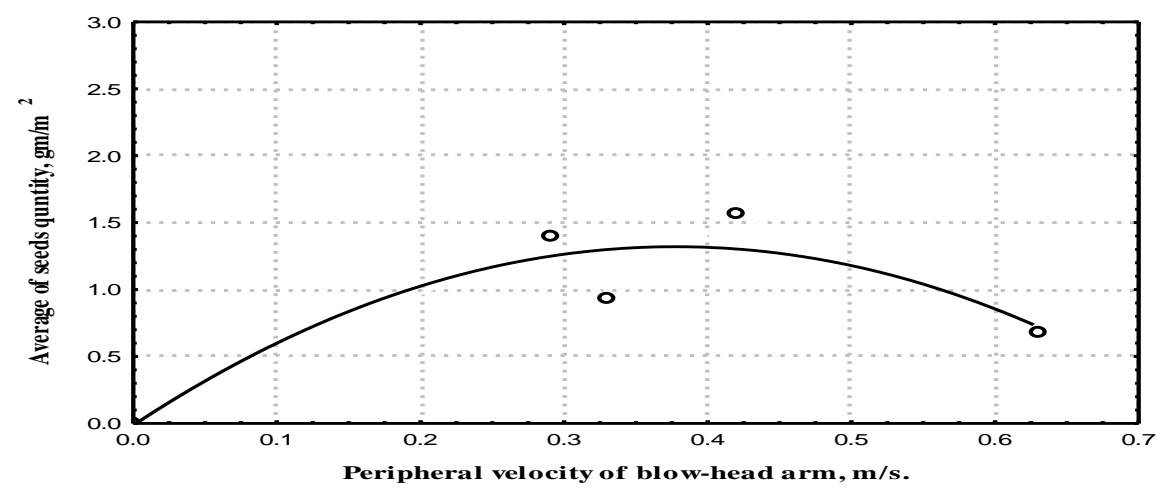

Fig. 15: Effect of peripheral velocity of blow-head arm on the average of seeds quantity for clover seeds.

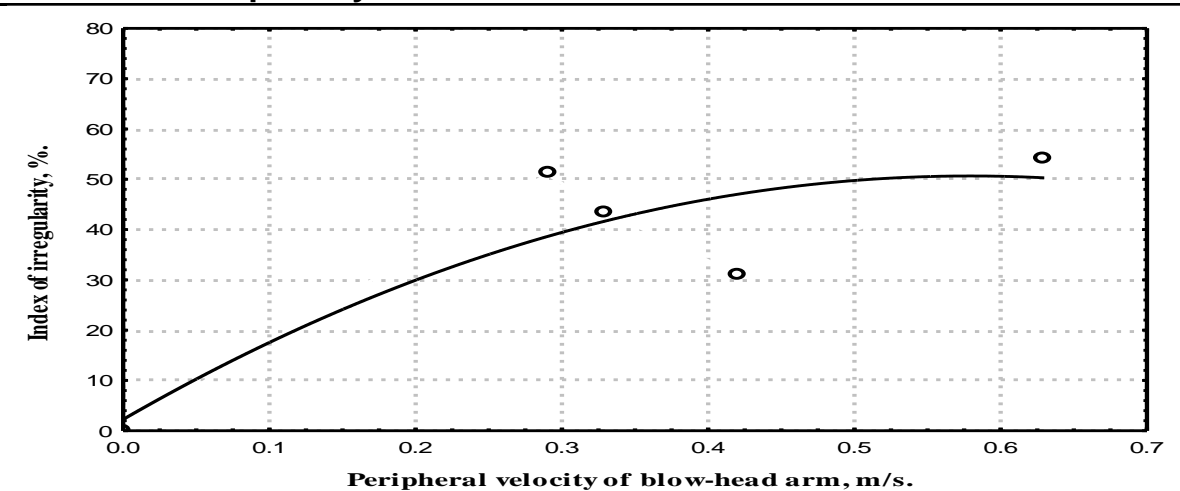

Fig. 16: Effect of peripheral velocity of blow-head arm on the index of irregularity for clover seeds. 
Sahhar,E. A. S.

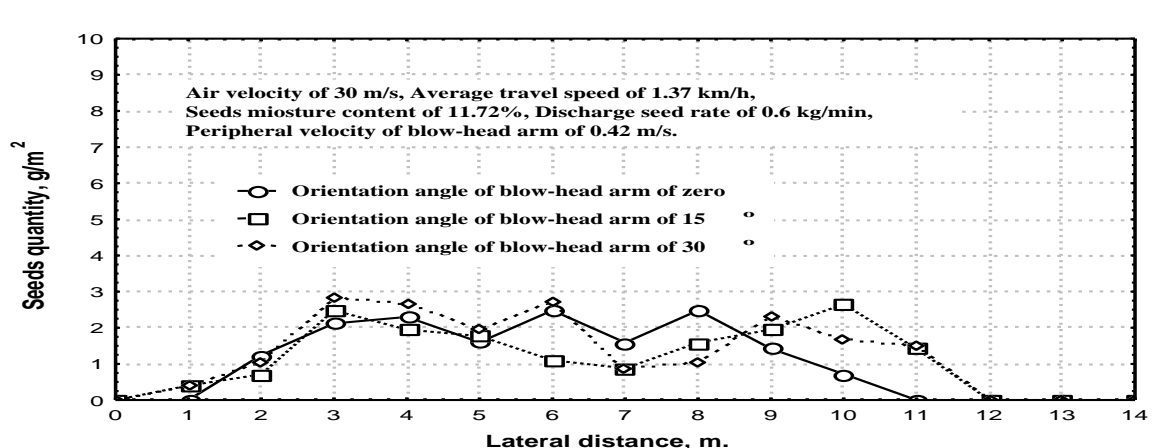

Fig. 17: Effect of orientation angle of blow-head arm on the distribution pattern for Egyptian clover seeds.

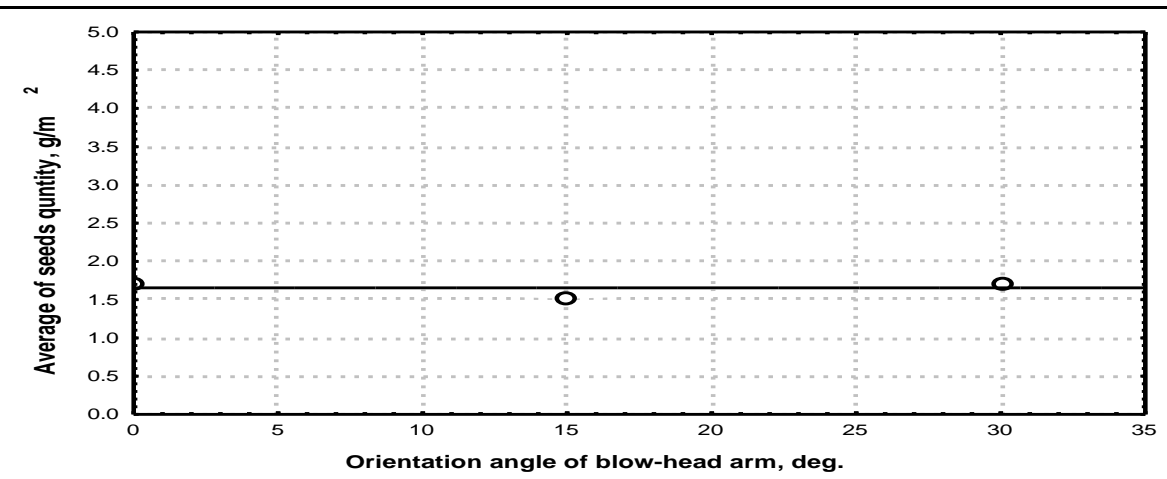

Fig. 18: Effect of orientation angle of blow-head arm on the average of seeds quantity for clover seeds.

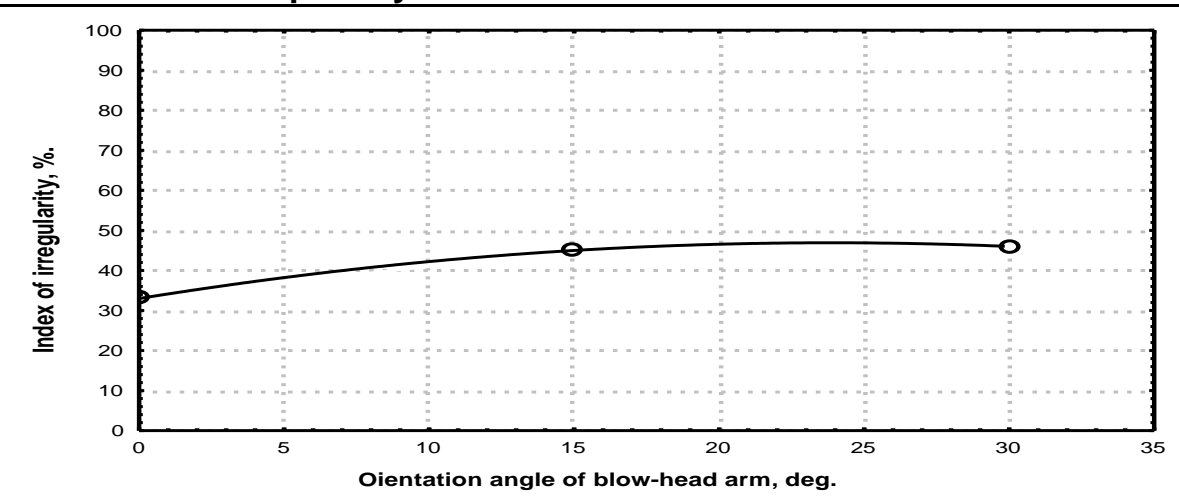

Fig. 19: Effect of orientation angle of blow-head arm on the index of irregularity for clover seeds. 
On the other hand, the index of irregularity for distributed seeds at zero degree orientation angle was less than that at $15^{\circ}$ and $30^{\circ}$ orientation angles by 36.4 and $45.5 \%$ resp. While, the index of irregularity at $15^{\circ}$ orientation angle was less than that at $30^{\circ}$ by $6.7 \%$. The increase in index of irregularity for distributed seeds at higher orientation angles of blow-head arm is attributed to increase the seeds scattering, which resulted in increase the length of the curved path traced out by the forced air. The difference between the index of irregularity at $15^{\circ}$ and $30^{\circ}$ orientation angles is too small, compared with the difference between $30^{\circ}$ orientation angle and either zero and $15^{\circ}$. This suggests that there is little gained from limiting the orientation angle of blow-head arm at angle of zero up to $30^{\circ}$. Therefore, the preferred orientation angle during broadcasting process is $30^{\circ}$.

6- Seeds moisture content: The results showed that the distribution pattern, seeding rate and index of irregularity for broadcasting clover seeds are related to the moisture content of seeds (Figs. 20, 21 and 22). Therefore, the results showed that distribution pattern of dry seeds $(11.77 \% \mathrm{~m}$. c.) was more intensity and uniformity than that soaked seeds (52.66 and $63.99 \%$ m. c.) due to the broadcasting process was carried out at bigger discharge seed rate of $2.5 \mathrm{~kg} / \mathrm{min}$. Meanwhile, the seeding rate decreased from 2.9 to $0.9 \mathrm{~g} / \mathrm{m}^{2}$ and index of irregularity for distributed seeds increased from 38 to $70 \%$ as the seeds moisture content increased from 11.77 to $63.99 \%$ resp. The decrease in seeding rate at higher seed moisture contents was due to increase the obstruction of flow seeds through discharge orifice from seed tank which resulted in the increased both agglomeration of seeds by cohesion action and physical characteristics of seed such as dimensions, volume, mass, density and sphericity as mentioned before in Table 1. On the other hand, the increase in irregularity index at higher seed moisture contents was attributed to the decreased seeding rate and consequently, increasing the seed quantity deviations from the average ones, as discussed before. From the previous results, a dry seeds of $11.77 \%$ m. c. was adequate to flow seeds easily during broadcasting process.

7- Overlapping percentage: The effect of the overlapping percent on the distribution pattern, seeding rate and index of irregularity for broadcasting clover seeds is shown in Figs. (23), (24) and (25). The results showed that seed distribution pattern with $50 \%$ overlapping percent were more seeds intensity than that any of the other overlapping percents (zero, 30 and $40 \%$ ). This is attributed to increase the seeding rate at higher overlapping percents. Meanwhile, the seeding rate increased from 1.5 to $2.6 \mathrm{~g} / \mathrm{m}^{2}$ as the overlapping percent increased from zero to $50 \%$. On the other hand, the index of irregularity for distributed seeds decreased from 60 to $40 \%$ by increasing the overlapping percent from zero to $50 \%$. The decrease in index of irregularity at higher overlapping percents was due to decrease the seed quantity deviations from the average ones, which resulted in increased the seeding rate. The difference between the seeding rate and index of irregularity at 40 and $50 \%$ overlapping percents are too small, compared with the difference between $50 \%$ overlapping percent and either zero, 30 and $40 \%$. This suggests that there is little gained from limiting the overlapping percent at percent of 40 up to $50 \%$. Therefore, the preferred overlapping percent during broadcasting process is $40 \%$. 


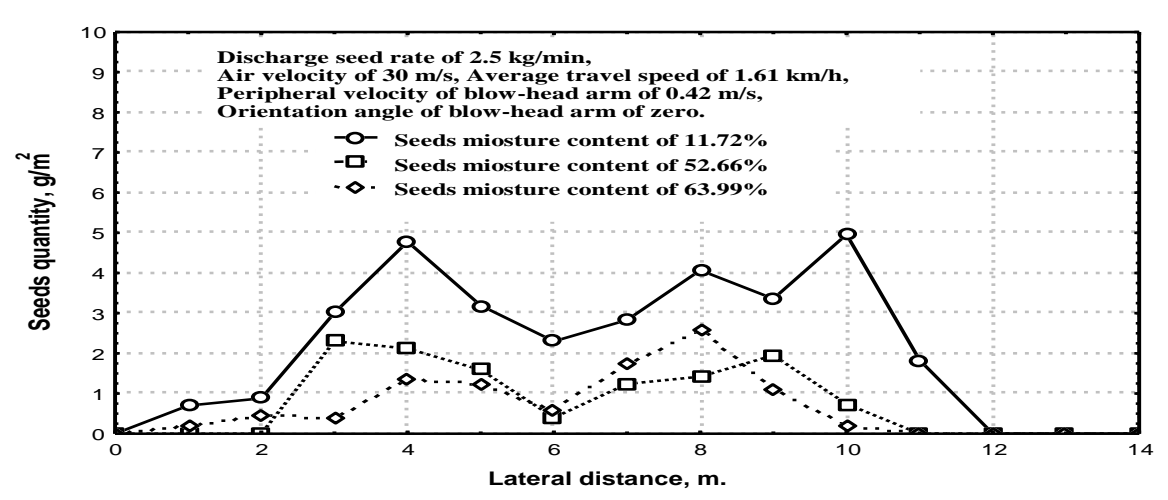

Fig. 20: Effect of seeds moisture content on the distribution pattern for Egyptian clover seeds.

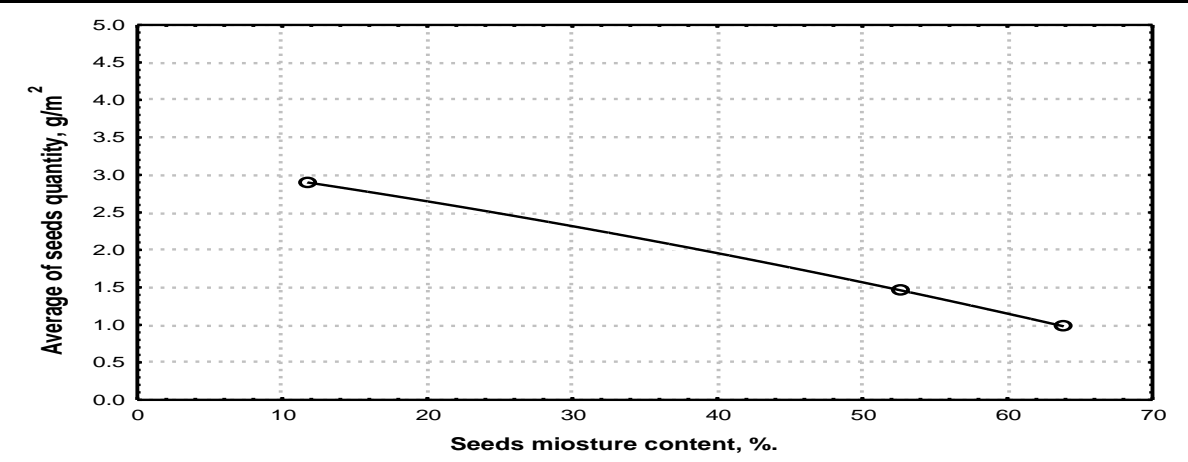

Fig. 21: Effect of seeds moisture content on the average of seeds quantity for clover seeds.

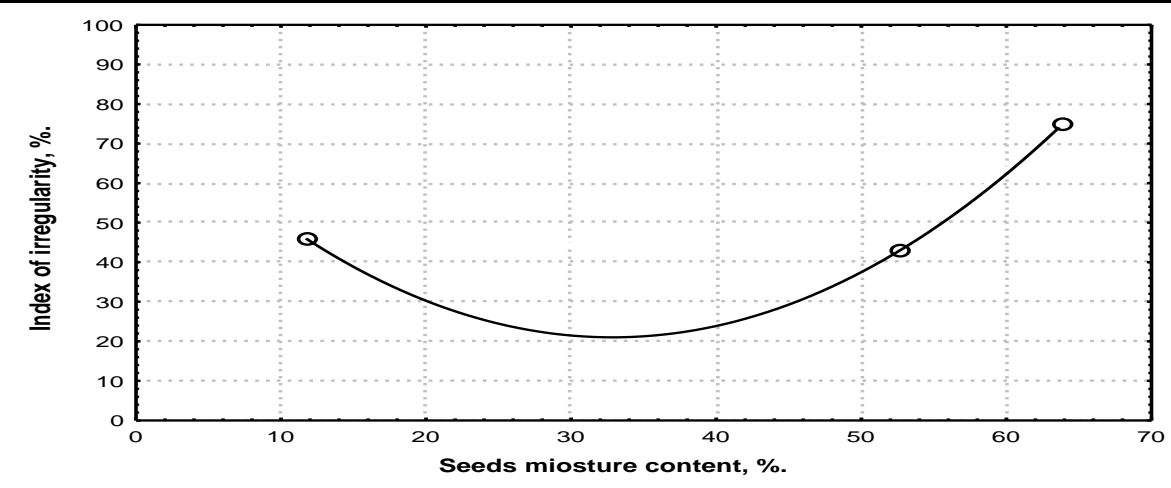

Fig. 22: Effect of seeds moisture content on the index of irregularity for clover seeds. 


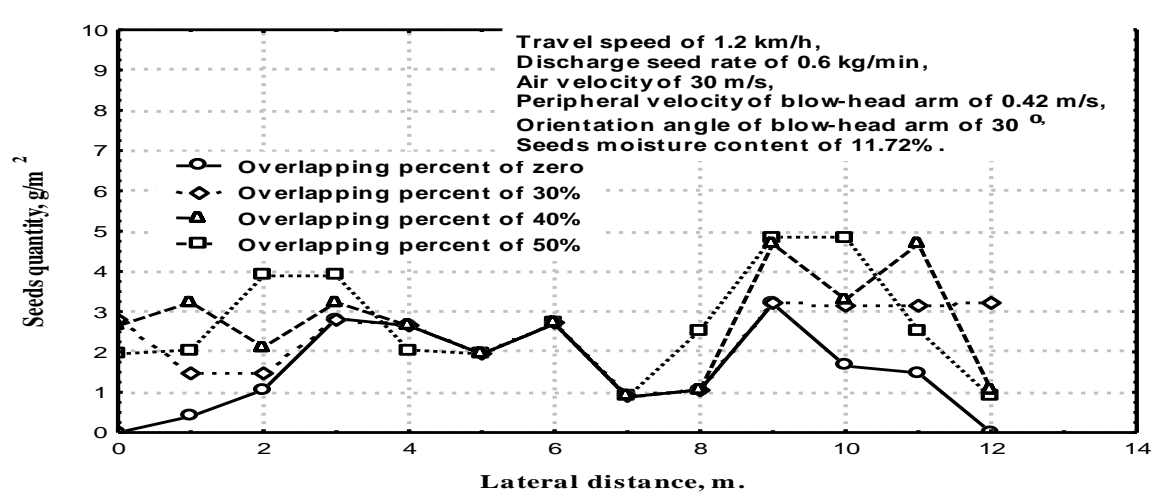

Fig. 23: Effect of overlapping percent on the distribution pattern for Egyptian clover seeds.

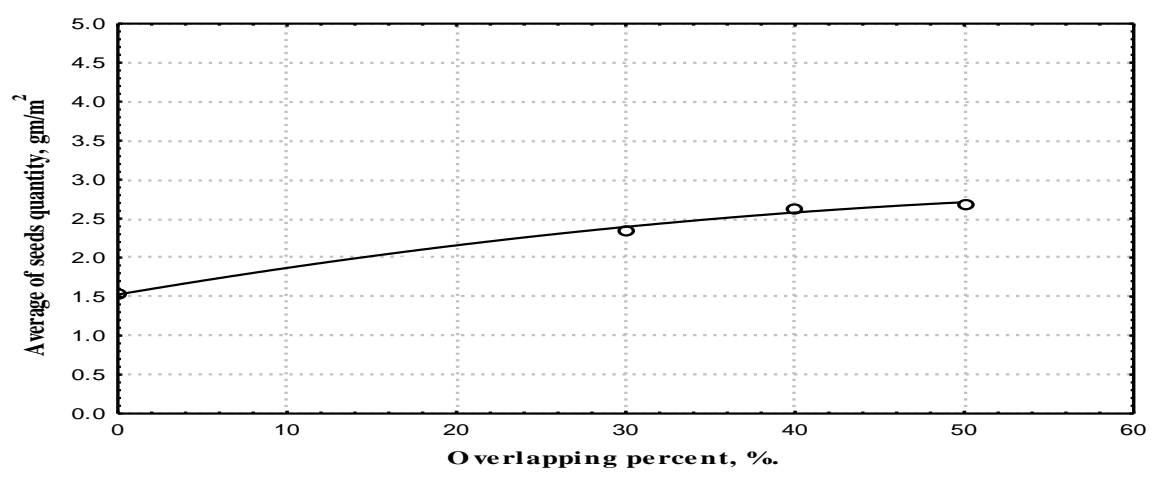

Fig. 24: Effect of overlapping percent on the average of seeds quantity for clover seeds.

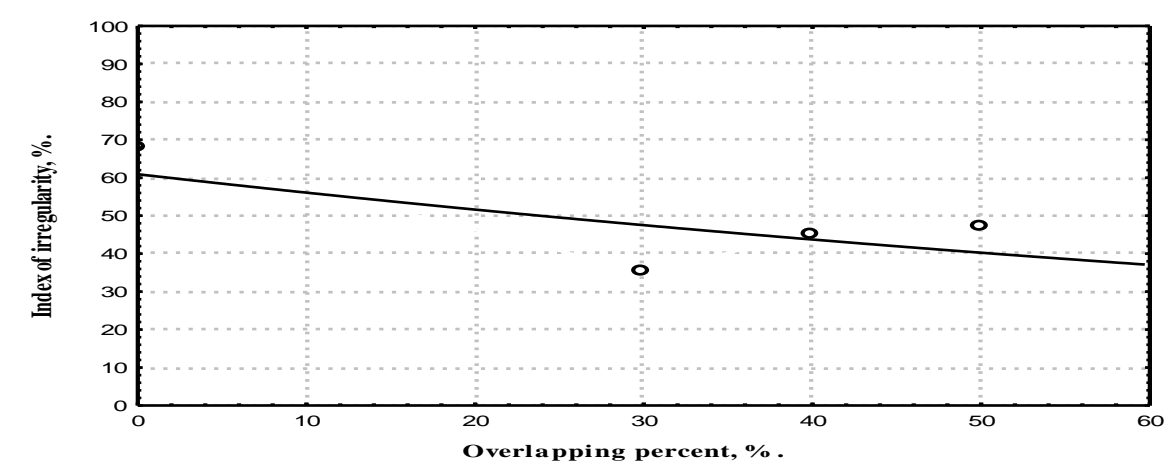

Fig. 25: Effect of overlapping percent on the index of irregularity for clover seeds. 


\section{CONCLUSION}

The research was carried out to study the possibility of using air stream of knapsack type power duster to broadcast seeds of Egyptian clover for optimum crop yields with minimum labor requirements and to investigate the factors affecting broadcasting process such as: travel speed of operator, broadcasting air velocity, discharge rate of seeds, peripheral velocity and orientation angle of blow-head, seeds moisture content and overlapping percent. Consequently, this research included these essential points:

1- In general, the knapsack type power duster proved function satisfactorily in Egyptian clover seeds broadcasting under the test conditions.

2- The most important factor affecting seeding rate and index of irregularity is the travel speed of operator. A low speed of $1.03 \mathrm{~km} / \mathrm{h}$ gave a higher seeding rate $\left(2.1 \mathrm{~g} / \mathrm{m}^{2}\right)$ and lower index of irregularity $(44 \%)$, while the high speed of $2.46 \mathrm{~km} / \mathrm{h}$ gave lower seeding rate $\left(1.5 \mathrm{~g} / \mathrm{m}^{2}\right)$ and higher index of irregularity $(48 \%)$.

3- The preferred air velocity to broadcasting the Egyptian clover seeds was found to be $30 \mathrm{~m} / \mathrm{s}$ as it resulted in higher seeding rate $\left(1.6 \mathrm{~g} / \mathrm{m}^{2}\right)$ and lower index of irregularity (30\%) than any of the other velocities.

4- The adequate theoretical discharge seed rate of broadcasting process by using knapsack duster for clover seeds is $0.71 \mathrm{~kg} / \mathrm{min}$ as it calculated from the recommended seed rate per one feddan which needs to $13 \mathrm{~kg}$ clover seeds.

5- The optimum peripheral velocity of blow-head arm during broadcasting process was found to be $0.42 \mathrm{~m} / \mathrm{s}$ as it resulted in higher seeding rate $\left(1.55 \mathrm{~g} / \mathrm{m}^{2}\right)$ and lower index of irregularity $(30 \%)$ than any of the other peripheral velocities.

6- There is no significant effect of the orientation angle of blow-head arm on the distribution pattern and seeding rate $\left(1.65 \mathrm{~g} / \mathrm{m}^{2}\right)$, and slight increase in the index of irregularity for broadcasting clover seeds. Therefore, the preferred orientation angle during broadcasting process was found to be $30^{\circ}$.

7- A dry seeds of $11.77 \% \mathrm{~m}$. c. was adequate to flow seeds easily during broadcasting process by using knapsack duster for clover seeds.

The preferred overlapping percent between distribution patterns during

broadcasting process by using knapsack duster for clover seeds was $40 \%$.

\section{REFERENCES}

Abdel-Gawad, A. A. and A. M. Abo Shetaia (1998). Production of Field Crops: p. 205. El-Anglo Egyptian Library. Cairo, Egypt.

Agric. Extension Issue (2006). Agriculture Economics Research Institute, Ministry of Agriculture, Cairo, Egypt: p. 53.

Amin, M. M. Abdel-Ghany, Y. A. El-Heany and A. S. Huzayyin (1988). Overlapping of Rotary Atomizers Spray Patterns. Misr J. Ag. Eng., 5 (2): pp. 149-158. 
Bernacki, H., J. Haman and Cz. Kanafojski (1972). Agricultural Machines, Theory and Construction: p. 615, Vol.1, National Technical Information Service, Springfield, Virginia, USA.

Bilanski, W. K. (1971). Aerodynamic Properties of Agricultural Products Research, Past and Present. Transactions of the ASAE, St. Joseph, Mich. 49085.

Griffis, C. L., D. W. Ritter and E. J. Mathews (1983). Simulation of Rotary Spreader Distribution Patterns. Transactions of the ASAE, 26(1):pp. 33-37.

Lee, K. C. and W. E. Yates (1977). A Rotary Cylinder Spreader for Aircraft Granular Applications. Transactions of the ASAE, 20(5): pp. 201-205.

Law S. E. and J. A. Collier (1973). Aerodynamic Resistance Coefficient's of Agriculture Particulate Determined by Elutriation. Transactions of the ASAE: pp. 918-922.

Mohsenin, N. N. (1986). Physical Properties of Plants and Animal Materials. pp. 5-8, 616-647. Gordon and Breach Science Publishers, Inc. New York, USA.

Omobuwajo, T. O. and E. A. Sanni (1999). Selected Physical, Mechanical, and Aerodynamic Properties of African Bread Fruit (Treculia Africana) Seeds. Journal of food Engineering, 40(4): pp. 241-244.

Snedecor, G. W. (1956). Statistical Methods, $5^{\text {th }}$ Ed. Iowa State University, Press. Ames, lowa, USA.

Yates, W. E., J. Stephenson, K. Lee and N. B. Akesson (1973). Dispersal of Granular Materials from Agriculture Aircraft. Transactions of the ASAE, 16(2): pp. 609-614.

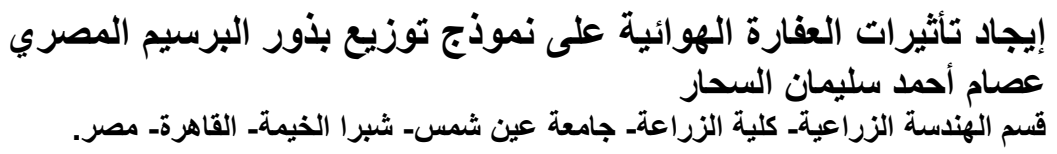

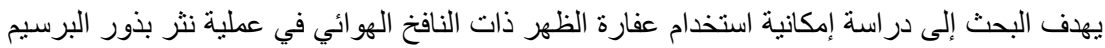

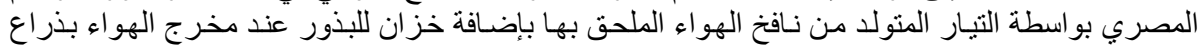

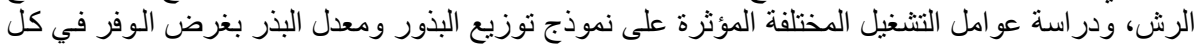

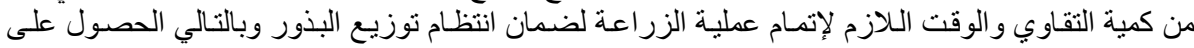

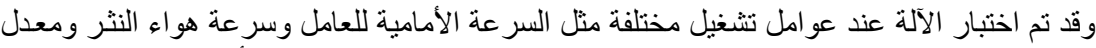

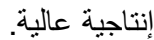

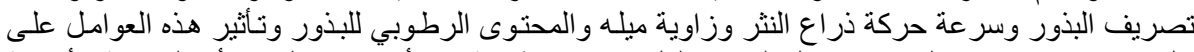

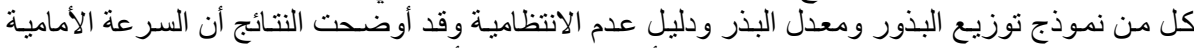

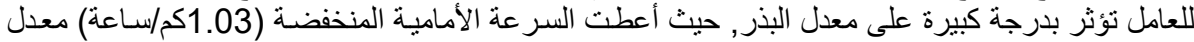

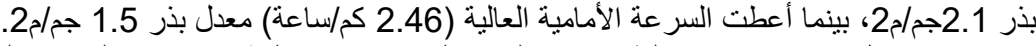

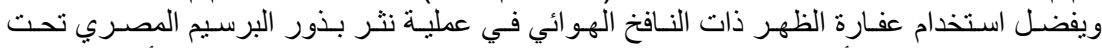

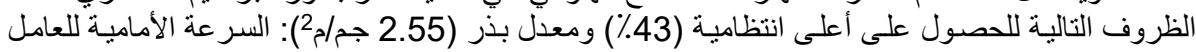

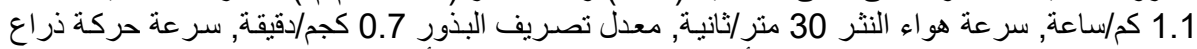

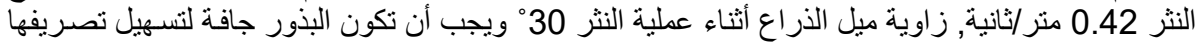

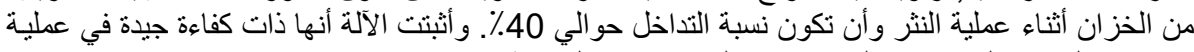
نثر بذور البرسيم الدصري و لكنها تحتاج إلى مزيد من الدراسة. 